\title{
We for She - Causes of Gender Discrimination in China and Corresponding Solutions
}

\author{
Ruixi Yan \\ Nanjing Foreign Language School \\ Amber1350@126.com
}

\begin{abstract}
Hate crimes fueled by gender discrimination are increasing in modern China, and the criticism of female victims seems a common phenomenon among Internet users. The author explores the deeper causes of such ingrained discrimination in the area of linguistics through two main aspects. First, women are unconsciously materialized when the praise they've long received focuses on their appearances instead of their virtues, while their identity is limited to wife, mother, or girlfriend in holiday slogans or advertisements. Second, when reporting such crimes, female victims are usually placed as subjects in sentences to attract the audience, which may shift the public's attention from the criminals to the imperfect details of victims. Based on the current situation, the author came up with several solutions for different social groups, including individuals, parents, celebrities, and the government.
\end{abstract}

Keywords: Denial of the victim, Misogyny, Materialization, Sentence Structure, Social responsibility.

I still remember how countless online articles and internet users strongly advocate that discrimination towards women is so radically eliminated in China today that fighting for gender equality is no longer one's social responsibility. Consequently, when I first saw the comment that "it is women's natural responsibility to undertake housework alone", I was quite sure it would be criticized severely. However, the 3 thousand "agrees" immediately overturned my initial thoughts.

While I start to reconsider the topic, an internet celebrity's experience in advocating feminism caught my attention. The feminist's Weibo blogs used to be blamed almost every day for "her" exaggeration of the difficult situations women faced and "her" logical fallacies when proving it was men's social responsibility to support women's independence. However, all the criticism suddenly terminated when the feminist accidentally revealed his true identity.

In our society, many "critics" seem to focus more on people's gender rather than people's behaviors; therefore, their rationality and sympathy can vanish in the face of all gender issues, showing an unreasonable antipathy towards female as a whole.

Situations can be even worse. Two months ago, when Global Times reported that a university student in Guangdong threw acid towards his female classmate, people were quick to hypothesize that she had probably cheated on him and thus deserved it; much earlier, when People's Daily disclosed that a stewardess was killed by a Didi driver when taking the taxi at night, people started to question if she was dressed too scantily. The public chose to ignore the fact of crime and immorality, while shifting their focus to alleged reasons that "explain" the tragedy of innocent victims and thus exonerate those flagrant criminals. Unless the woman harmed is a "perfect victim" like Lamu who was hardworking and optimistic but was eventually beaten to death by her own husband, certain people will always be willing to justify the rationality of a crime towards women.
Many of these people are misogynists, and some of their actions can be recognized as a new type of terrorism. These examples only reveal a miniscule glimpse of the suppression of women, but they prove that gender fueled hate crimes are not confined to any particular group or ideology; indeed, it is now permeating our life through misogyny, which violates hundreds of women's security and liberty.

Exploring the deeper cause of misogyny, we can find that animosity or unconscious materialization of females is already stealthily rooted in our language system. According to the research done by a study group regarding sexuality from Beijing Normal University, among a Chinese university's slogans celebrating International Women's Day from 2016 to $2020,48 \%$ focuses on relationships and $20 \%$ is related with description of appearances, while only $6.7 \%$ praises female students' talents and abilities. At a festival originally set to pursue female liberalization, almost all of the slogans were written under the male gaze; in contrast, women's voices deteriorate, and they are forced to become the object described and defined by others. It seems like women have become the protagonists in writings nowadays, but these protagonists are stereotyped and passively controlled, since women's appearances are still judged by men, and their positions are still limited to girlfriends and family members.

The hidden discrimination to females can be further demonstrated in one type of specific sentence structure that the public is used to. According to the famous feminist Julia Kristeva's hypothesis, when people read a sentence, they usually tend to be more focused on the sentence's subject. Moreover, according to a psychological study by Harvard in 2016, when people read news regarding violence or crime, if the victims are placed at the position of subject in every sentence, the victims then become the epicenter of the situation rather than the crime or the criminals. As the epicenter, the victims are scrutinized over every single detail of their lives by the readers, their imperfections often blown out of proportion. Such cognitive bias is a natural flaw of human's subconscious, but it is widely applied by Chinese social media or newspapers when reporting events regarding 
vulnerable groups, especially women, since appalling titles that directly mention the victims usually have a better effect on attracting readers. Take Pengpai News, a newspaper that is generally considered as impersonal and objective, as an example. Among its 180 publications that placed women at the position of subject in 2019, only 7 of them had positive content (such as a female enterprise donating a large sum of money or a female doctor saving several children's lives), whereas the other 159 pieces of news had totally negative content full of exaggerated descriptions relating to violence or sex (such as a wife killed by her husband, or a girl raped by her schoolmate).

It is really the time to make a change. For individuals, it is their responsibility to remember that they should not assess somebody based on gender simply, they should not find explanations for the crime but always focus on victims' infringed rights, and they should not be entitled to such moral superiority as to comment on others' appearances and emotional states. For society, it's parents' responsibility to educate their sons the importance of respecting women and regulating their behaviors, it's celebrities' responsibility to stand out and phonate for women humiliated or harassed, and it's the government's responsibility to make citizens aware of the existed prejudice and unconscious animosity towards women, while make legislations to detailize protections for women and then execute strict retaliation against anyone violating such legislations.

Pursing gender equality is fundamentally pursing equality for all, since women should be first entitled as human beings. Therefore, we should be ensured to live free from violence and discrimination, according to the universal declaration of human rights. If anyone wants to be treated with equality and justice, then it is he or she's social responsibility to eradicate misogyny or prejudice towards women.

Fortunately, more and more people, especially women themselves, have recognized such responsibility. Emma Waston, a famous actress, zealously made several speeches for the UN Women campaign HeForShe while Yangli, a popular talk show star, bravely made several jokes revealing the imperceptible sexual harass that woman experience sometimes from conversations with men. As long as everyone is able and willing to break the silence, improvements can be made, and our society's future is worth looking forward to. 